\title{
A model for optimizing plans for procurement of raw materials from regions of Russia in a timber-processing enterprise
}

\author{
Rodion S. Rogulin \\ E-mail: rafassiaofusa@mail.ru \\ Vladivostok State University of Economics and Service \\ Address: 41, Gogolya Street, Vladivostok 690014, Russia \\ Far Eastern Federal University \\ Address: 10, Ajax Bay, Russky Island, Vladivostok 690922, Russia
}

\begin{abstract}
In this paper a model for the formation of sustainable supply chains of raw materials for a timber processing complex is proposed. The model allows one to optimize the plan of purchases from the Russian Commodity Exchange, as well as the plan of manufacturing finished products. The model presents the task of mathematical programming, whereby the company's profit is used as the objective function, and the input data include the forecasted values of structure and volumes of offers available on the Russian Commodity Exchange, as well as demand for finished products. The recurrence dependencies of the model describe the flow of raw materials at the enterprise's warehouse, taking into account revenues from purchased lots, transportation time and consumption of resources that are required for production of simulated volumes of products. Constraints of the model represent formalization of the limited flow of financial resources, taking into account sales and warehouse characteristics. The optimization task deals with variables including volumes of daily output of finished products according to a given nomenclature, as well as variables that specify the inclusion of lots into the portfolio of applications purchased on the exchange. The model solution is found using the branch and bound method with preliminary clipping based on the modified Chvatal-Gomory method. One example considers formation of optimal plans for the purchase and sales in a timber processing complex located in the Primorsky Territory (Russia), which does not have its own forest plots providing production with raw materials. The usefulness of the interaction of the enterprise with the timber department of the commodity and raw materials exchange is assessed.
\end{abstract}


Key words: supply chain; enterprise economics; timber exchange; data analysis; resource consumption rate; warehouse capacity.

Citation: Rogulin R.S. (2020) A model for optimizing plans for procurement of raw materials from regions of Russia in a timber-processing enterprise. Business Informatics, vol. 14, no 4, pp. 19-35.

DOI: 10.17323/2587-814X.2020.4.19.35

\section{Introduction}

I $n$ any industry of the economy, production is a quite complex and time-consuming process. When managing the manufacturing process, there are many tasks that have different levels of complexity. Such tasks require appropriate tools to optimal solutions determining. In its development strategy, an enterprise can focus on goals that are different from the financial point of view. In most cases, this goal is to maximize profit, which amount depends on multiple factors coming from both the external and internal environment of the enterprise.

Typically, the entire manufacturing process can be subdivided into three stages. The first stage is securing the material resources (raw materials). The second stage is production. The third stage is sale of the finished products, including logistics issues.

Each of these processes is quite complex in its own way. A serious problem for any production in the timber industry is to obtain resources [1]. If the necessary raw materials are purchased outside the enterprise, then the enterprise faces the task of selecting the best option for purchasing and delivering raw materials from the production areas to the production site. For a timber industry enterprise that buys raw materials on a commodity exchange, the number of possible options on a planning horizon of several months is quite large. This requires analysis of significant volumes of data and the use of special tools [2, 3].

Another important issue is the problem of selecting the optimal volume of products for each type, taking into account current market demand $[3,4]$. However, it is difficult and even dangerous for the prospect of the enterprise to form a production plan on the middle or longrange planning horizons without understanding the current situation on the raw materials market. It may turn out that the prices for raw materials are too high to purchase in sufficient quantities, while the production plan is drawn up relying on the availability of certain types of raw materials. In this regard, for high-quality planning of production volumes, it is important to take into account the trends on the raw materials market.

To solve the task of arriving at an optimal manufacturing plan, it is necessary to develop the plan on the basis of the available forecasts for raw materials, or relying on the known distribution of orders sold in the market. So, there is a question that is known in the literature as the problem of supply chain management (SCM).

\section{Review of the literature and stating the problem}

The tasks of supply chain management (SCM) are always complex from several points of view. First, there is no exact universal method for finding optimal (or more or less effective) solutions of SCM problems [4]. Secondly, there are a huge number of factors that must be taken into account when looking for solutions $[1,3,5]$.

The timber industry has its own specifics of the raw material delivery process. Raw materials from this industry are very similar to food products, because both have a time factor - the factor of the stock availability. If a commodity is stored for too long, then there is a high probability that it will deteriorate and lose liquidity. Therefore, the speed of delivery of raw materi- 
als to the point of production should be maximized [2, 3].

To achieve the maximum speed of delivery of raw materials, so that raw materials remain liquid for the manufacturer, the following is essential. First, it is necessary to know the distribution of market bids [1]. Second, one should take into account the delivery time of raw materials $[4,6]$. Finally, you must take into account the important factor of the number of consumed types of raw materials per unit of manufactured goods, and also take into account the stock of each raw material and storage capacity.

The authors of [7] developed one of the rare purely linear models for the raw material delivery system. By transforming a linear programming problem into a two-step scenario-based problem, it is possible to eliminate uncertainty in production levels and weather conditions. The scenario based model allowed the authors to minimize overall costs, including transportation, warehouse expansion and throughput penalties.

Authors of [4] solved the problem of forming a supply chain, taking into account the norms of labor costs for the production of each unit of goods. The authors modeled the situation for the delivery of the final product to consumers by forming a matrix of input and output flows. The indicator of the difference between the sales revenue and the costs of transporting goods was used as an objective function. It should be noted that the solution of this problem has a one-time nature for the current situation, and for solving subsequent tasks of the supply of goods it will be necessary to solve this problem again. This is extremely difficult from the point of view of the volume of appropriate computations.

Article [8] discusses a new multi-period, multi-product supply chain project that takes into account economic, environmental and social aspects. The model aims to minimize the total cost of the system, including the fixed costs of installation, transportation, manufacturing, purchasing, distribution and environ- mental protection. The model considers several aspects of supply chain network design, such as capacity of facilities, maximum coverage radius, limited budget and the acceptable level for social assessment of enterprises and distribution centers. The model captures various categories of uncertainty, including on the supplier side and the receiver side. To deal with undefined parameters, a limited fuzzy programming approach is used. Several test tasks are used to analyze the characteristics of the problem proposed. The results of the calculations show that accounting for the different categories of uncertainty is critical to designing an efficient and effective supply chain network. The disadvantages of this model include failure to account for the delivery of raw materials to the point of production, as well as the maximum volume of raw materials and goods that can be simultaneously stored in warehouses.

The authors of [9] argue that a decline in market prices leads to the need to reduce the cost of supplying wood chips to ensure profitability in the supply chain and continued supply of wood chips. Shredding and transporting are two main factors affecting the overall cost of a biofuel supply system. In order to fully utilize the payload of trucks and reduce transport costs, logging residues are usually cleaved at planting so that there is a minimum of empty space between the raw materials. It is important for the contractor to maximize the proportion of effective working time in relation to the planned working time. It is now widely believed that effective working time is less than 50 percent of planned working time due to transporting chips using a crusher, waiting for trucks for chips and other delays. The increased loading of the shredder requires more efficient coordination between the equipment and the chip loaders that deliver the produced chips to the customer. Supply system models were constructed using discrete event simulation to examine how transport distance, number of trucks, shift scheduling and chip buffers affect system costs for a high-performance crusher 
system. System cost and machine utilization vary greatly depending on system configuration.

In [10], the authors proposed a new approach for re-optimization of transportation plans for $\log$ trucks in real time when an unexpected event is detected. This approach uses a spacetime network to represent the evolution of the transport network over time and the changes it undergoes after a failure. Permitted trips and loading / unloading operations are used as input to the mathematical model. The last solution represents the final transportation plan. The simulation procedure was designed to generate unexpected events for real world applications. Compared to the full informational scenario, where it is assumed that the failures are known in advance, the proposed approach yields very good results. In addition, as the authors argue, the mathematical model was solved in a few seconds and thus is well suited for real-time use. However, it should be noted that the authors do not account for various additional factors such as production and warehouse capacity.

The authors of [11] proposed using the genetic algorithm (GA) to find a set of Pareto optimal solutions for a multipurpose supply chain with four echelons, using two different weighting approaches. The authors of [12] developed a model for the supply of raw materials using a two-tier assembly system under conditions of uncertain lead times in order to minimize the expected cost of storage of components and maximize the level of customer service. They used two GA-based multipurpose metaheuristics to solve these problems. In [13], supply networks based on GA (in particular, knowledge-based genetic algorithm, KBGA) for optimization are provided. In [14], a multipurpose model of mixed integer programming for a closed loop network design was formulated. In addition to total costs, the model optimizes total carbon emissions and network responsiveness. An advanced genetic algorithm based on the NSGA II structure was designed to obtain Pareto optimal solutions.
In addition, in [15], the authors considered a two-stage stochastic programming model used for the design and management of biodiesel supply chains in various types of production. The model reflects the impact of uncertainty in the supply of biomass and technology on supply chain decisions. The authors solved this problem using algorithms that combine Lagrange relaxation and L-shaped solution methods.

Based on the review of literature, it can be assumed that the topic of the formation of supply chains for raw materials has been seriously studied in the literature and, due to the lack of common approaches to solving this problem, has a high degree of relevance. In addition, there are no works that would consider the possibility of supplying raw materials from commodity exchanges, taking into account various production restrictions.

Thus, the purpose of this study is to develop a method for the formation of optimal plans for the purchase of raw materials from a commodity exchange and manufacturing of finished products. Such a plan should ensure the maximum profit of the enterprise before tax at a given planning horizon, in order to assess the possibilities of cooperation between the enterprise and the exchange.

To achieve the goal, the following tasks were set:

$\downarrow$ to develop a mathematical model that maximizes the profit of an enterprise based on optimization of procurement planning and production volumes using a forecast of the structure and volume of proposals on the Russian Commodity Exchange, as well as demand for finished products;

$\downarrow$ to test the model in a real enterprise and explore the computational aspects of using the model;

$\downarrow$ to propose an approach to assessing the possibilities of cooperation between the enterprise and the exchange. 


\section{A model for the formation of an optimal plan for the procurement of raw materials and the manufacturing of finished products}

A typical timber processing enterprise may be able to lease a plot (to win a tender), find plots in the nearest district (the legal form of leased forest plots) and to purchase raw materials from this plot, as well as to consider alternative sources of raw materials supply, including external sources $[16,17]$. Next, we will consider enterprises that purchase raw materials from external sources. To test the model, one of the enterprises of the Primorsky Territory of Russia is considered.

Thus, we consider the problem of forming optimal plans for the purchase of raw materials and production of products by a manufacturing company of the timber processing industry at a given planning horizon $M$, taking into account the offers on the market from the timber industry and the demand for finished products.

At the initial moment of time $m=0$, there is planning of raw materials procurement and production for the entire given horizon $m \in\{0,1, \ldots, M\}$. On this horizon, for each $m$-th day, a set of offers on the raw material market (in the form of orders on the commodity exchange) and the demand for manufactured products on the market for the period under consideration are given. The market order is set by the region of the logging company, the volume and the price, including the cost of delivery. The demand in the market for finished goods is determined by the possible selling price for each type of product.

We will consider the accumulated profit as the objective function of the model.

Let's introduce the following parameters and variables:

$l$ - type of raw materials for the production of finished products $l=1, \ldots, L$;

$$
k \text { - type of production } k=1, \ldots, K \text {; }
$$

$c_{i l r m}-$ purchase price of the $i$-th application for raw materials of the $l$-th type in the $r$-th region on the $m$-th day (rubles), including the cost of delivery; $v_{i l r m}$ - volume of raw materials of type $l$ in request $i$ from region $r$ per day $m$ (cubic meters);

$u_{l m}-$ stock of raw materials type $l$ per day $m$ (cubic meters);

$u^{\max }$ - maximum storage capacity (cubic meters);

$\dot{v}_{\text {ilrm }}-$ volumes of type $l$ raw materials purchased in the previous period, for which it is known that they will arrive at the warehouse on a day $m$ (cubic meters);

$A_{l k}$ - the volume of resource $l$ spent on the production of a unit of goods $k$ (cubic meters);

$p_{k m}-$ selling price of product type $k$ in day (rubles);

$z_{k}$ - cost of production minus the cost of the main raw materials used (timber);

$F C$ - fixed costs per day (rubles);

$x_{k m}$ - production volume of goods type $k$ in day $m$ (units);

$l$ - the number of orders that were purchased by the enterprise in the previous period (until the moment $m=0$ ), and for which the dates of arrival at the warehouse are known;

$R$ - the number of regions from which orders are placed (raw materials are mined and put up for auction) on the exchange;

$T_{r}$ - the rate of time spent (in days) for the delivery of any volume of raw materials from region $r$ by rail;

$Q_{\operatorname{lnkm}}-$ demand from consumer on item $n$ in $k$ day $m$;

$M$ - the planning horizon under consideration (days), called the current period;

$\dot{M}$ - the number of days from the current period for which purchased orders will arrive at the warehouse during the next period;

Budget $_{0}$ - the company's budget allocated for the introduction of trading, as of the moment the model starts working;

$\dot{x}_{k m}-$ hypothetical production volume of product type $k$ in day $m=1: \dot{M}$, which can be determined as: 


$$
\begin{aligned}
\dot{x}_{k m} & =\left\lceil\frac { 1 } { 2 } \left(\max _{m^{*} \in[m-t, m]}\left(x_{k m^{*}}, \dot{x}_{k\left(m^{*}-1\right)}\right)+\right.\right. \\
& \left.\left.+\min _{m^{*} \in[m-t, m]}\left(x_{k m^{*}}, \dot{x}_{k\left(m^{*}-1\right)}\right)\right)\right],
\end{aligned}
$$

where $t-$ the number of days for which the maximum and minimum values are selected $x_{k m^{*}}$ in constraints (3) and (4), respectively (mathematical notation of constraints is given below).

Parameters $u_{t 0}$ and Budget $_{0}$ are determined and set and correspond to the last day of the previous period.

As an objective function, we will consider the pre-tax profit of the enterprise on the planning horizon $M$.

As a result, the mathematical formulation of the problem is as follows:

$$
\begin{gathered}
\sum_{k, m}\left(p_{k m}-z_{k}\right) x_{k m}-\sum_{i, l, r, m} c_{i l r m} y_{i l r m} \rightarrow \max \\
u_{l m}=u_{l(m-1)}+\sum_{i, r} v_{i l r\left(m-T_{r}\right)} y_{i l r\left(m-T_{r}\right)}+ \\
+\sum_{i \in I, r \in R} \dot{v i l r m}_{i r}-\sum_{k} A_{l k} x_{k m}, l=1: L, m=1: M \\
\sum_{l} u_{l m} \leq u^{\max }, m=1: M+\dot{M} \\
u_{l m} \geq u^{m i n}, l=1: L, m=1: M+\dot{M} \\
\sum_{k} A_{l k} x_{k m} \leq u_{l m}, l=1: L, m=1: M \\
y_{i l r m}=\left\{\begin{array}{c}
1, \text { if lot } i \text { with resourse type } l \\
\text { in region } r \text { in day } m \text { is bought } \\
0, \text { otherwise } \\
\text { Budget }{ }_{0}+\sum_{m=1}^{m^{*}}\left(\sum_{k}\left(p_{k m}-z_{k}\right) x_{k m}-\right. \\
\left.-\sum_{i, l, r} c_{i l r m} y_{i l r m}-F C\right) \geq 0, m^{*}=1: M \\
x_{k m} \leq \sum_{n} Q_{n k m}, k=1: K, m=1: M
\end{array}\right.
\end{gathered}
$$

$$
\begin{gathered}
\text { Budget }_{0}=\text { const } \\
u_{l 0}=\text { const } \\
u_{l m}, x_{k m} \in Z^{+} \\
u_{l m}=u_{l(m-1)}+\sum_{i, r} v_{i l r\left(m-T_{r}\right)} y_{i l\left(m-T_{r}\right)}+\sum_{i \in I, r \in R} \dot{v}_{i l r m}- \\
-\sum_{k} A_{l k} \dot{x}_{k m}, l=1: L, m=M+1: \dot{M}
\end{gathered}
$$

Expression (1) is an objective function that reflects the total profit of production. Expression (2) reflects the recurrent ratio of the stock of each type of raw material as of every day, depending on the planning period. Expressions (3) and (4) guarantee the availability of raw materials in the warehouse within the range between the minimum stock and the maximum storage capacity. Expression (5) means that the total amount of consumed resource of each type will not exceed the stock of the corresponding type of raw material in the warehouse on day $m$. Expression (6) reflects the decision made. Expression (7) reflects the minimum budget per day $m^{*}$. Expression (8) limits the volume of production by demand in the market. Expressions (9) and (10) are input data. Expression (11) guarantees the integer value of the solution obtained. Note that expression (12) does not participate in the search for the optimal solution, therefore, formula (12) is used after the found optimal solution of model (1-11).

The subtracted part in the objective function (1) deserves special attention. The enterprise is unable to purchase part of the lot due to the specifics of the commodity exchange. Therefore, in the model (1-12), in the subtracted part of the objective function, there is a binary variable $y_{i l r m}$. In other 
words, the company either takes the full ${ }^{1}$ lot (and then pays a fixed cost for the full volume of raw materials in the application, including the delivery cost), or refuses to buy the whole.

The model $(1-11)$ is a linear integer programming problem. Let's note some features of this problem. The first is that the number of variables grows at a polynomial rate $\left(O\left(\alpha^{4}\right)\right)$. The second is that the number of constraints with a high probability imposes serious complexity on the search for the first feasible solution, since the polyhedral admissible set of solutions can sharply decrease $[15,18,19]$.

To solve the problem, we will use the branch and bound method with preliminary cutting by the modified Gomorri method included in the system MathWorks².

\section{Model testing and calibration}

For approbation of the model, the company "DNS Wood" LLC was chosen. The company carries out continuous production of certain types of goods. For certain administrative reasons beyond the control of the company, it cannot lease areas for the extraction of raw materials. Therefore, the company is considering the possibility of purchasing raw materials from the regions of the Russian Federation through the St. Petersburg International Commodity ${ }^{3}$ and Raw Materials Exchange (hereinafter "exchange"). The company uses two main types of raw materials: sawlogs $(l=1)$ and pulpwood $(l=2)$. More detailed sub-types of raw materials do not matter due to manufacturing features. Data on the results of trading on the exchange are posted on the official website, where one can see the transactions for any period.

To test the model, data from the "DNS Wood" enterprise and the exchange for five months (from 01 February 2019 to 31 July 2019) were used. During this period, 752 applications were submitted for all types of raw materials that are of interest to the enterprise. According to the exchange data, during this period logging enterprises from four regions participated in the auctions as sellers of raw materials: Irkutsk Region ( $r=1)$, Republic of Udmurtia $(r=2)$, Moscow Region $(r=3)$ and Perm Territory $(r=4)$. Since the exchange does not disclose the real names and locations of the sellers, there is no more detailed information about them. During the specified period, an array of the following data was collected: prices of orders offered $c_{i r m}$, volumes of orders $v_{i r m}$, sales prices of final goods $p_{k m}$, number of orders for each type of raw material. In addition, relying on the analysis of the company's sales statistics, we assume that the daily demand for each type of product is set on the considered planning horizon $\sum_{n} Q_{n k m}{ }^{4}$.

We assume that the prices $p_{k m}$ at which goods are sold on the market are fixed and do not change within the planning horizon. We also consider three cases of enterprise pricing pol-

\footnotetext{
1 This lot already includes shipping costs, because the enterprise in question does not have the ability to independently deliver the purchased raw materials to its warehouse. It is worth clarifying here that if the buyer is able to independently deliver raw materials, then the value of the $c_{i l r m}$ parameter can have two meanings: including and not including the cost of delivery. If the company chooses between registration of delivery and refusal to receive, then such a decision can be considered as a modification of this model.

2 MathWorks. Documentation. Mixed-Integer Linear Programming Algorithms: https:// it.mathworks.com/help/optim/ug/mixed-integer-linear-programming-algorithms.html

3 Official website of the St. Petersburg International Commodity Exchange (JSC "SPIMEX”): https://spimex.com/markets/wood/trades/results/

4 For further research in the field of process modeling in the field of SCM, it is planned to forecast the demand for the manufacturer's products based on the data available to the enterprise. However, in this work, already recorded volume of demand for 2019 was used. This data was used for the assessment of the possibility of interaction between the enterprise and the exchange
} 
icy. In the first case, the prices of the settlement period coincide with the prices at which the company sold goods during the period from January to July 2019. In the second case, the prices of the previous period increase by $5 \%$, which is approximately the same as the inflation rate. In the third option, the company improves the quality of its products and believes that it can increase prices by an amount exceeding inflation by two times. The daily volume of demand of each type will be set as a uniformly distributed random variable in the interval from 0 to 15 . With an increase in the price for the percentage of inflation, we assume that such a trend is characteristic of the market as a whole, therefore, demand does not change. When price dynamics are higher than changes in the market as a whole, we assume that the price elasticity of demand is approximately equal to one. To consider the change in profit for each pricing policy, we carry out 50 realizations of determining the optimal solutions to the problem and average the profit indicators.
The main source data characterizing the enterprise are presented in tables 1 and 2.

Let's consider the instrumental part of the problem. The calculations were performed on a computer with 16 GB RAM and a 12-thread Ryzon 2600x processor. We used 'intlinprog' as a built-in function, which is an integral part of the Matlab programming language. We used the following data as input arrays for the builtin function:

$\downarrow$ objective function multiplied by $-1^{7}$;

$\checkmark$ integer constraints for all model variables;

$\downarrow$ constraint matrices;

$\downarrow$ vectors of the right sides for constraints, such as equalities and inequalities;

$\downarrow$ lower and upper bounds of variable values;

$\downarrow$ starting point for finding a solution (empty vector);

$\downarrow$ the maximum number of vertices of the polyhedral set of feasible solutions that the algorithm can pass (units).

\section{The main input parameters of the "DNS-Wood" enterprise}

Table 1.

\begin{tabular}{c|c} 
Parameter, units measurements & Parameter value \\
$u^{\text {max }}$, cubic meters & 7500 \\
\hline$u^{\text {min }}$, cubic meters & 100 \\
\hline$u_{l 0}{ }^{5}$, cubic meters & $(1550 ; 1550)$ \\
\hline$p_{k m}, \forall m \geq 0, k=1: 9$, '000 rubles & $(22.1 ; 32.8 ; 40.8 ; 43.7 ; 45.5 ; 48.5 ; 57.5 ; 60.5 ; 66.9)^{6}$ \\
\hline$T_{r}$, days & $(3 ; 5 ; 6 ; 5)$ \\
\hline Budget $_{0}$, rubles & $10,000,000$ \\
\hline$F C$, rubles & $1,000,000$ \\
\hline
\end{tabular}

Source: "DNS Wood" LLC (http://dns-les.ru/)

\footnotetext{
5 Input data, as of initial moment of the algorithm's run $(m=0)$

6 Prices of final goods, with numbers. At these prices, the company sold goods on the market for five months in a row

7 Multiplication by $(-1)$ is explained by the specifics of the "intlinprog" built-in function. By default, it is aimed at finding the minimum value of the objective function. More detailed information about this function is available at: https://www.mathworks.com/help/optim/ug/intlinprog.html
} 
Raw materials costs for production of a unit of each of goods

\begin{tabular}{c|c|c|c|c|c|c|c|c|c|c} 
Recourse type $(l)$ / item number $(k)$ & $\mathbf{1}$ & $\mathbf{2}$ & $\mathbf{3}$ & $\mathbf{4}$ & $\mathbf{5}$ & $\mathbf{6}$ & $\mathbf{7}$ & $\mathbf{8}$ & $\mathbf{9}$ & $\sum_{k} A_{l k}$ \\
\hline 1 & 2 & 5 & 6 & 6 & 6 & 5 & 8 & 8 & 12 & 58 \\
\hline 2 & 3 & 4 & 5 & 6 & 8 & 10 & 9 & 10 & 7 & 62 \\
\hline
\end{tabular}

Source: "DNS Wood" LLC (http://dns-les.ru/)

Since the problem has a large dimension, we cannot guarantee that the optimal solution will be found in suitable time, so it was decided to restrict the number of traversed vertices of the set of feasible solutions to $10^{7}$ units. If a solution has been found, but the algorithm has left the loop due to the above constraint, then we assumed that the solution is not optimal, but "conditionally effective."

\section{Discussion}

During testing, an optimal solution was obtained. The algorithm running time was 124.32 seconds; 87,562 vertices were passed. Let us consider in more detail the results of solving the problem of supplying raw materials to the company's warehouse.

Figures 1 and $2^{8}$ show the visualization of the volumes of stock $u_{l m}$ of raw materials $l$ for each day $m$. The darker color reflects the stock of raw materials in the warehouse, the lighter color - its receipt $v_{l m}$. It can be seen that the stock did not fall below the value $u^{m i n}=100$ cubic meters and did not exceed $u^{\max }=7500$ cubic meters. In addition, it should be noted that the warehousing time of the resource $l=2$, on average, exceeds the same time for $l=1$. This is due to the rate of consumption of raw materials $A_{l k}$ per unit of goods. The main arrival of raw materials $l=1$ falls on March, April and May. The main arrivals of raw materials $l=2$ falls on February and March. The intensity of the supply of raw materials $l=1$ is higher than that of $l=2$, which is related with the rates of production costs $A_{l k}$. Additionally, we note that the stock of raw materials in the warehouse changes significantly, which indicates the complexity of planning the procurement of raw materials.

Figure 3 shows the total stock of raw materials in the warehouse. It can be seen that all five cases, when the stock of raw materials in the warehouse was at its maximum, occurred in February and March. This is due to the fact that stock of raw materials of the second type were at their maximum during these months. Figure 3 shows that the threshold value of the minimum volume of raw materials in the warehouse was reached only once - at the end of the planning period. Except for this moment, the minimum recorded volume of raw materials in the warehouse did not fall (second half of April, 84 day of planning) below 990 cubic meters. Figure 3 also shows that the planning of raw material supply chains is an extremely difficult task, since the fluctuations in the volume of raw materials in the warehouse are very large. Therefore, it makes sense for an enterprise to consider the possibility of expanding the storage capacity.

\footnotetext{
8 All figures, except for $4 \mathrm{a}$ and $4 \mathrm{~b}$, refer to the case when prices are set without inflation adjustments
} 


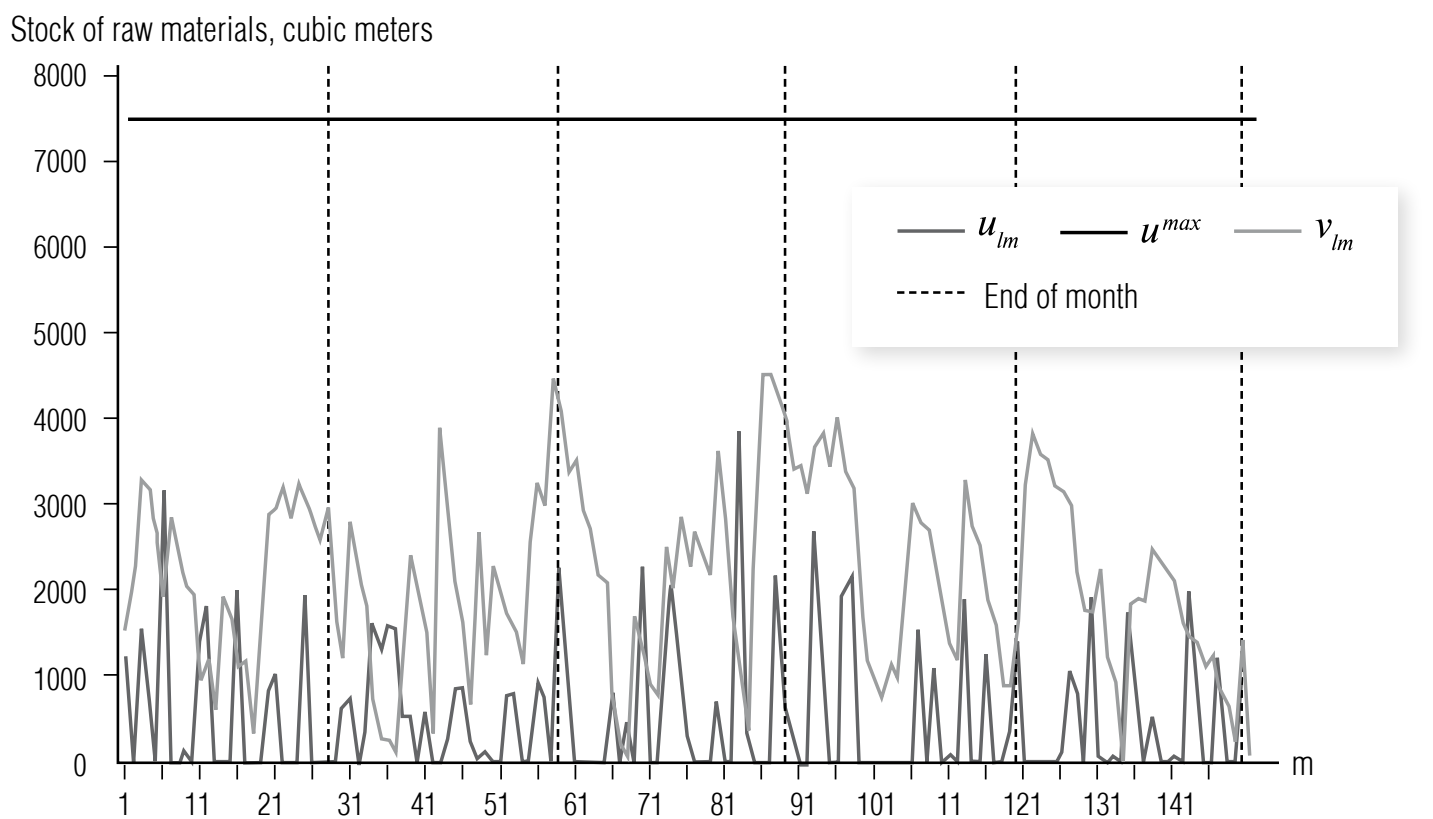

Fig. 1. Visualization of receipt and the current state of stocks of raw materials in the warehouse at a time interval $m=1, \ldots, M$, recourse type $l=1$

Stock of raw materials, cubic meters

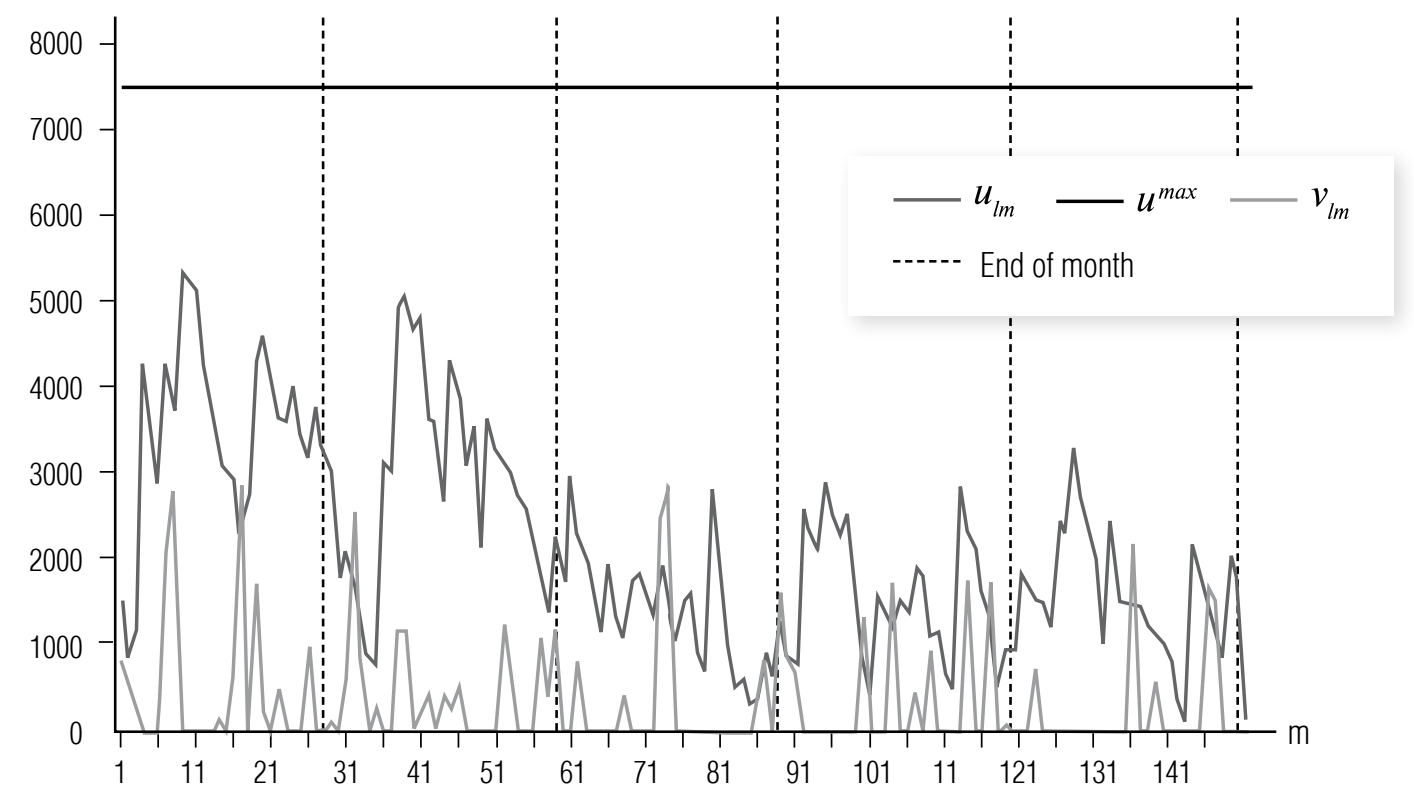

Fig. 2. Visualization of receipt and the current state of stocks of raw materials in the warehouse at a time interval $m=1, \ldots, M$, recourse type $l=2$

Figures $4 a$ and $4 b$ show the visualization of the average values of the company's accumulated and daily profit, respectively. The lines in the figures indicate profit without taking into account price increases during the planning horizon, in the case of five percent price increase 


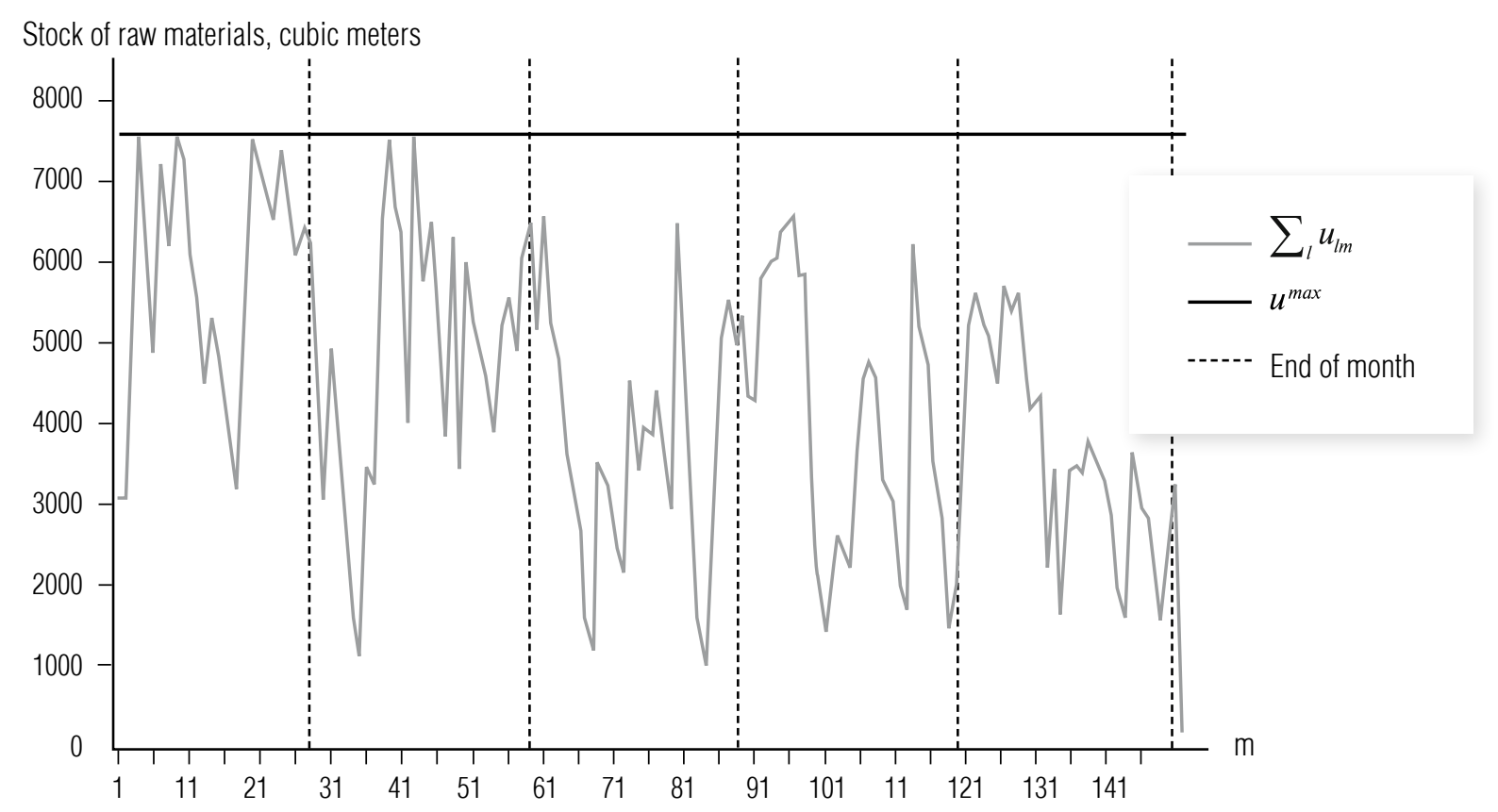

Fig. 3. Visualization of the current state of the total stock of all types of raw materials in the warehouse $\sum_{l} u_{l m}$ every day

$\left(p_{k m}=1.05 p_{k m}\right)^{9}$, and in the case of a ten percent increase in prices $\left(p_{k m}=1.01 p_{k m}\right)$. It can be seen that the total value of profit stabilizes ${ }^{10}$ after April. This is due to demand, which is weakening by the summer, that is to say, there is a seasonality factor.

Let's consider Figures 5 and 6 in details. The figures show the volumes of purchased raw materials $l=1$ and $l=2$ from each region by month. The lower bar indicates the volume of raw materials purchased in the region. The sum of the higher (superstructure) and the lower bars indicates the volume of raw materials put up for auction by the region in the corresponding month. It follows from the figures that most of the raw materials came from the Irkutsk Region. This phenomenon is explained by the fact that the maximum volume of raw materials (relative to all participants in the exchange) is put up for auction in this region. You should also take into account that the delivery time from the Irkutsk
Region is minimal. However, in April it was recorded (Figure 5) that the volume of raw materials received from the Perm Territory is approximately the same as the volume received from the Irkutsk Region. In addition, in February (Figure 6), it was recorded that the volumes of raw materials received from the Perm Territory were not lower than the volumes of raw materials purchased in the Irkutsk Region, despite the fact that every month the volume of raw materials in the Irkutsk Region is traded in large volumes. This is due to raw material prices. Prices for raw materials in the Irkutsk Region are higher than in any other region, which is explained by the proximity of this region to China. In particular, there is a direct railway line to the PRC, where entrepreneurs buy raw materials at high prices. In the Perm Territory, prices are much lower, and it is geographically more remote from China. Hence, we can conclude that in practice the enterprise should monitor the raw materials

\footnotetext{
9 In this paragraph the "_" sign means the operation of re-assignment

${ }^{10}$ According to the data from "DNS Wood" company
} 


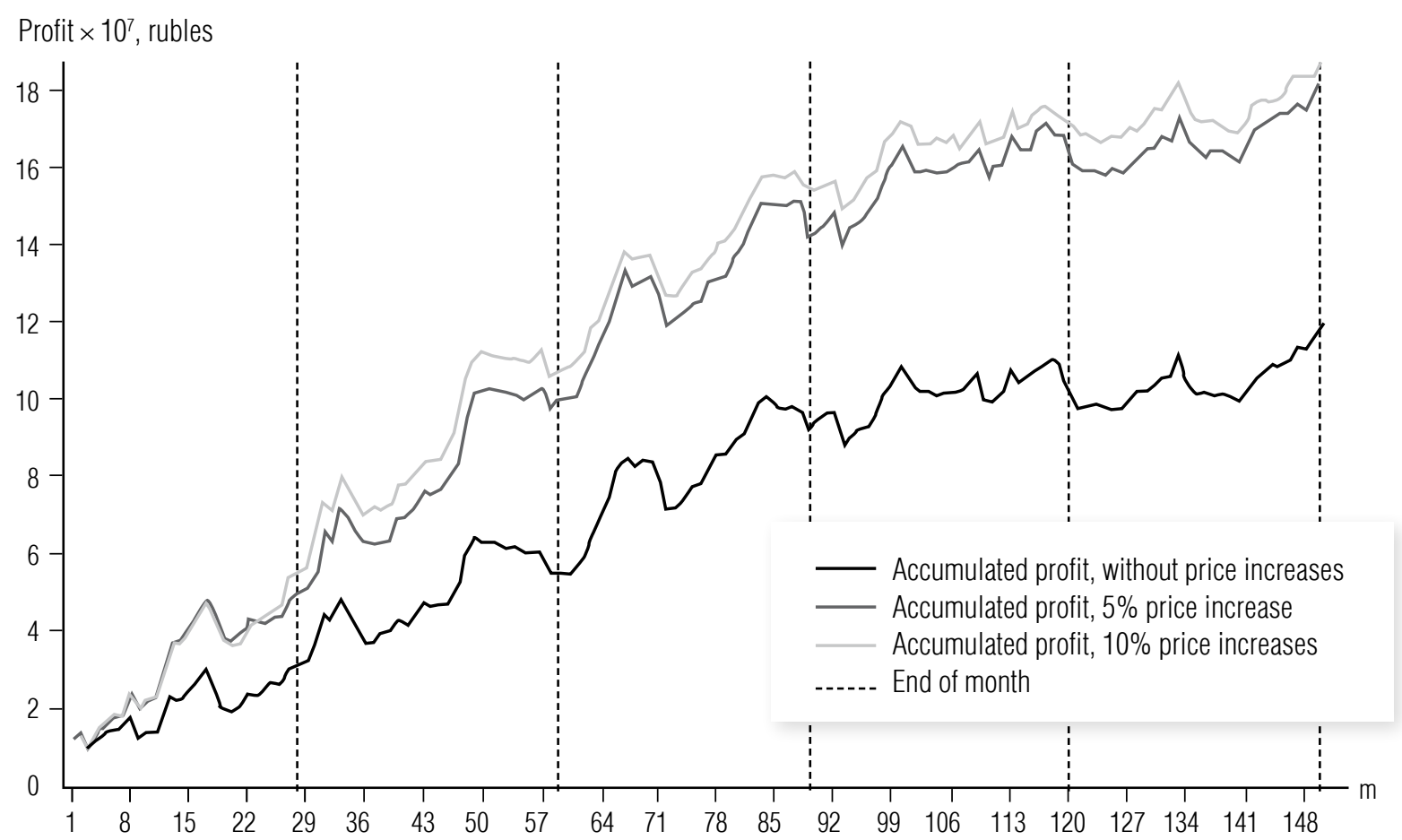

Fig. 4a. Visualization of the average accumulated profit of the enterprise

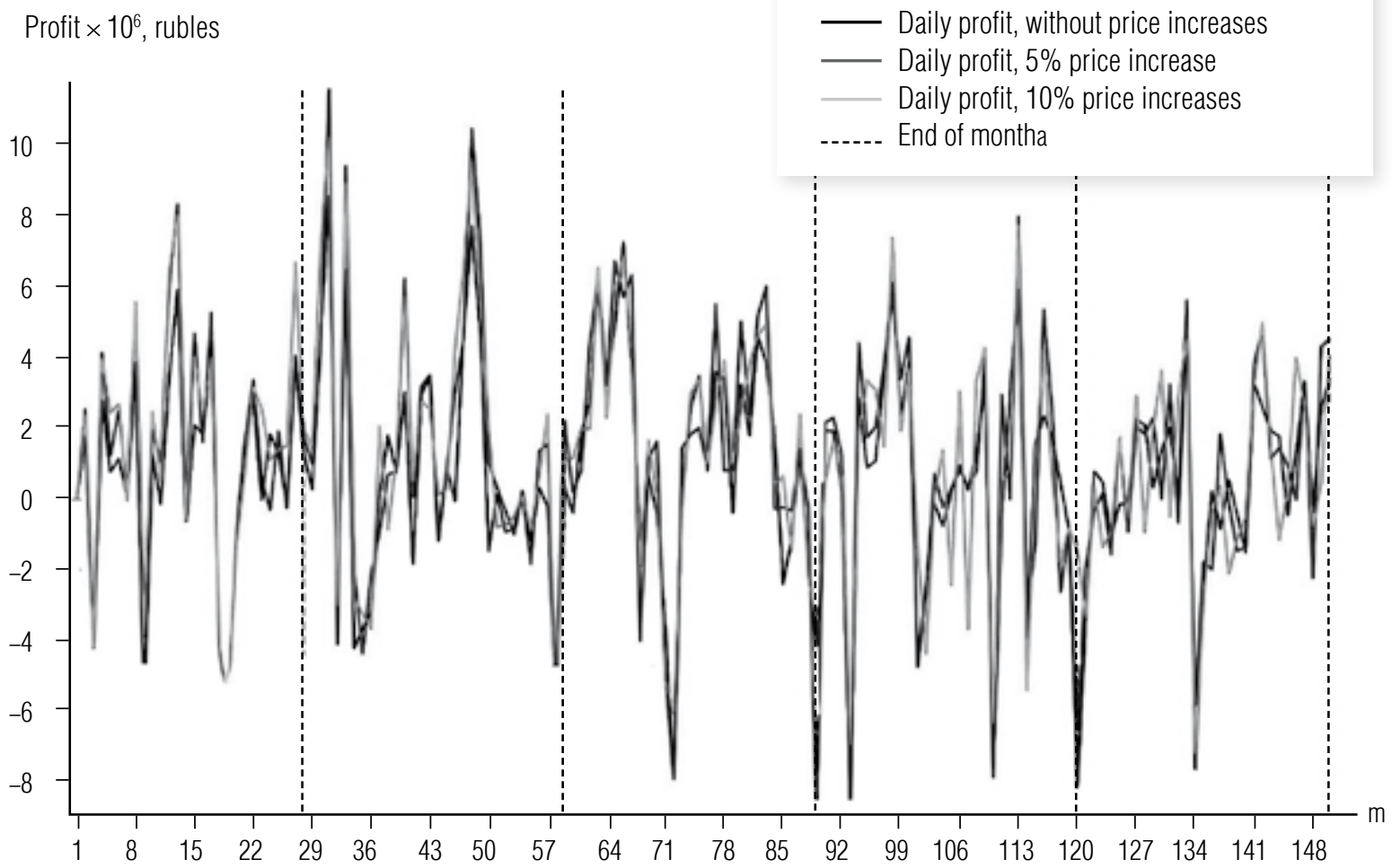

Fig. 4b. Visualization of the average daily profit of the enterprise 
market in the Perm Territory. If a raw material is put up for auction in this region, then it should be closely viewed as a potential purchase.

In addition, we note that in terms of the volume of raw materials produced, the Perm Territory ranks second out of the four considered regions. The volume of export of raw materials from the remaining regions is of no interest, since in aggregate, it does not exceed $30 \%$ of the total volume received from the Irkutsk Region and the Perm Territory.

It also follows from Figures 5 and 6 that the volume of extracted raw materials of any type decreases as the spring and summer approaches. This is due to transportation problems related with the extraction of raw materials. As a rule, production units are carried out with a trick, which, if opened by the supervisory authorities, entails administrative and criminal liability, as well as the revocation of the lease of the site for the extraction of raw materials. The fact is that the Ministry of Natural Resources and Ecology of the Russian Federation approves the norms for deforestation every year by quarters. However, since it is more difficult to extract raw materials during the period of off-season thaw and high summer temperatures, entrepreneurs cut down more in winter than should be in a quarter. Then in the annual reporting they distribute the extracted volume according to the instructions of the Ministry (which undoubtedly leads to improper exploitation of forest resources). This trend can be seen in Figures 5 and $6^{11}$.

The pairs of Figures $(1,5)$ and $(2,6)$ should be considered separately. It can be seen from them that the volume of purchased products is also decreasing, which affects the stabilization of the value of accumulated profit (Figure 4).

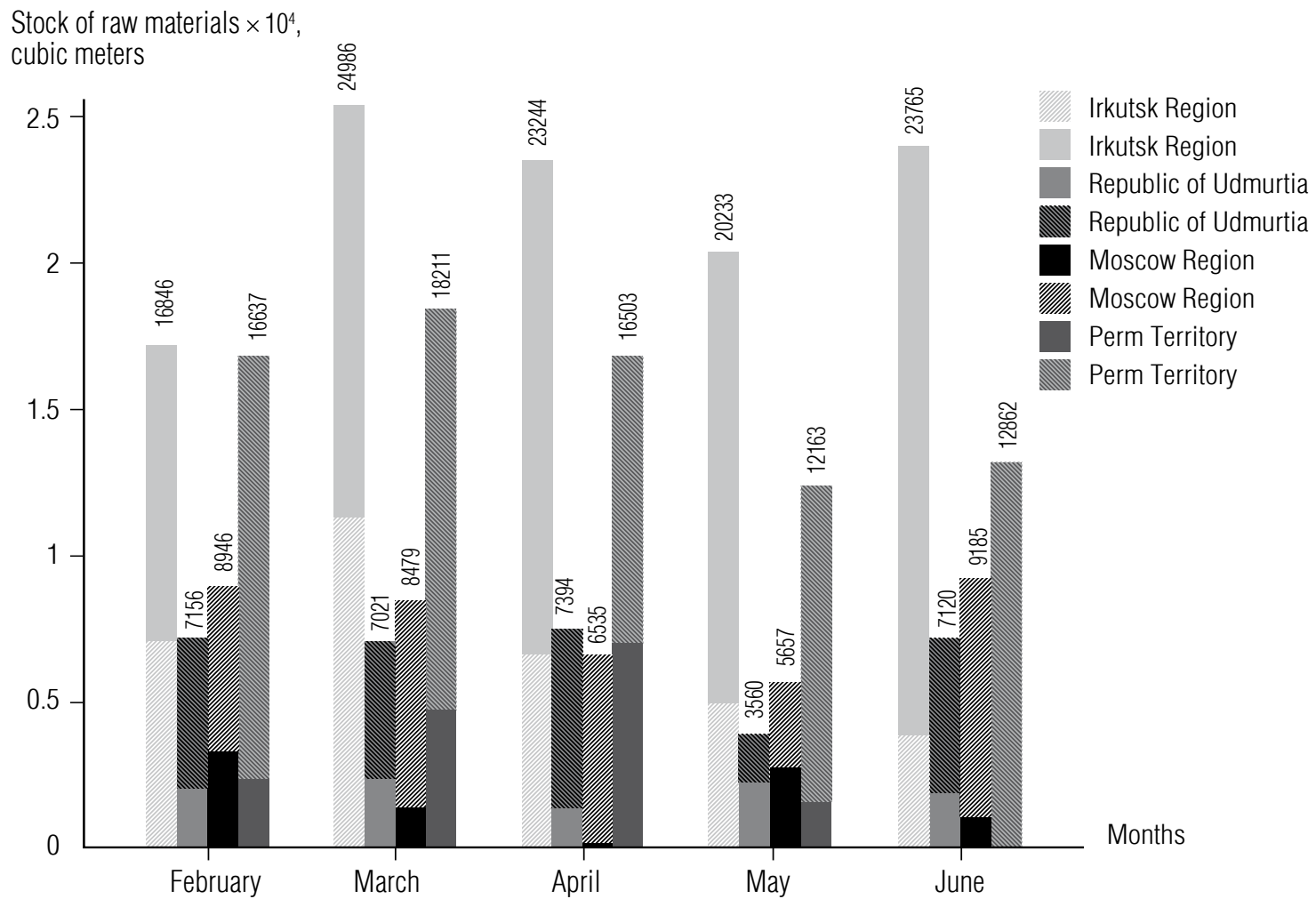

Fig. 5. Visualization of the extracted volumes of raw materials in each region by months

\footnotetext{
${ }^{11}$ Note that these exchanges only show the volume of transactions, but the same conclusions can be drawn from them
} 


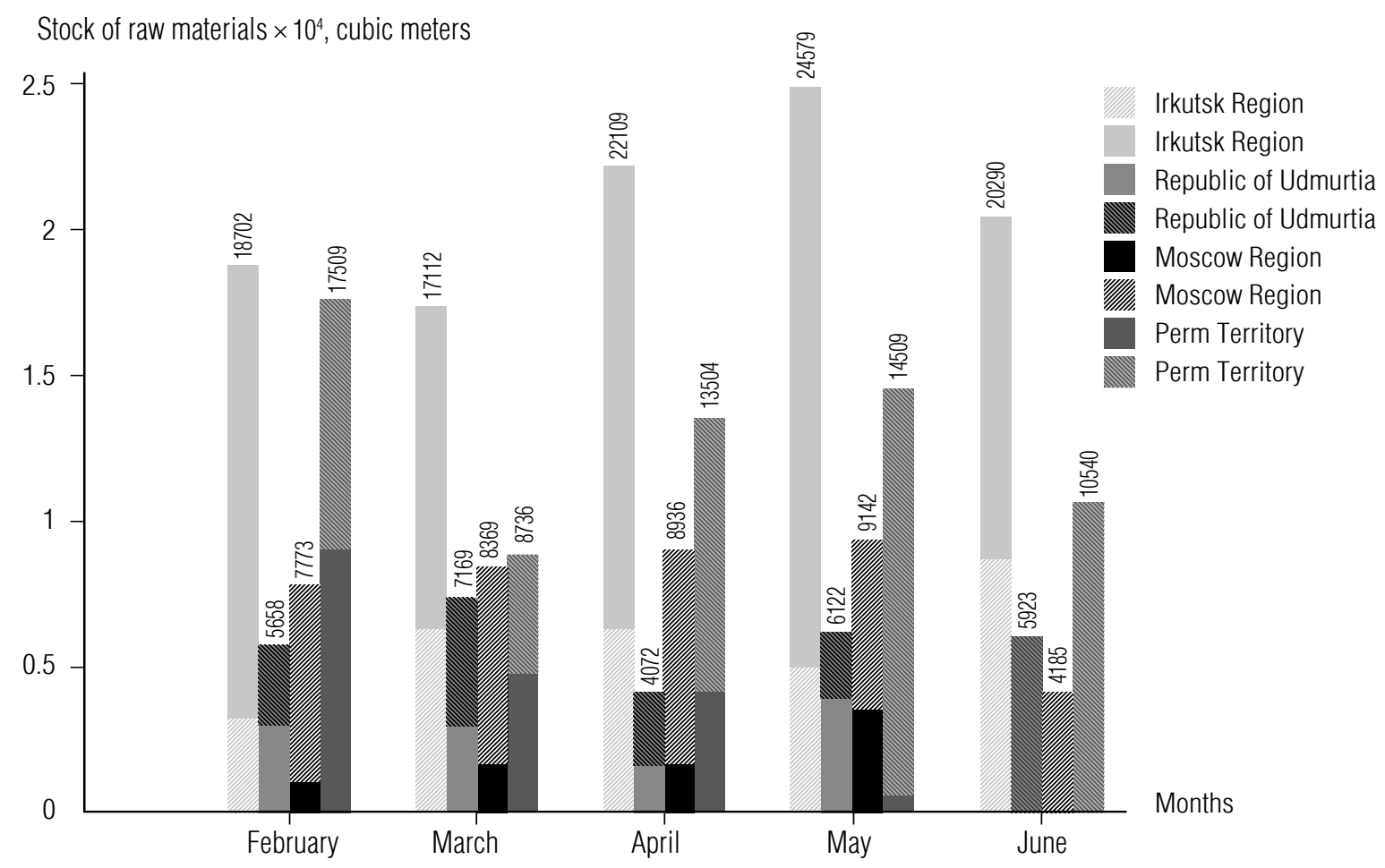

Fig. 6. Visualization of the extracted volumes of raw materials in each region by months

Let's consider Figure 7, which shows a visualization of the production volumes of each product of the enterprise by month. This figure reflects the consequences of a decrease in market demand in the market by summer and, accordingly, the stabilization of the growth of accumulated profit (Figure 4a).

It can be noted that the volumes of production of goods of types 1 and 8 by summer increase (in comparison with May), despite the fact that the statistics of purchases of these types of goods shows a decline in production.

It can also be argued that the volume of production of goods of type 2 should decrease as summer approaches.

Let's consider the behavior of the production volumes of goods 3, 4, 5 and 9 . The volume of products sold by March reaches its peak (3, 4, 9), while after this month the volume of products of these types is constantly falling. The exception is the product of type 5: for it, rise and fall of production are monotonous (the maxi- mum production volume was reached in April, but after that there was a decline).

The exception to the general rule on reducing the volume of sales of each type of product was product 6 . It shows a steady growth in comparison with winter and early spring. Thus, the production should pay attention to its further release in the summer.

Note that the production volume of type 7 is somewhat more complex than the others. Here you can clearly see the "jumping" trend of production. However, we can definitely say that this type of product has always been included in the production plan to a large extent and, accordingly, it makes sense to include it in the summer production plan.

It should be noted that when delivering raw materials to a consumer in the timber industry, there is a peculiarity: enterprises often refuse to accept raw materials if they are on the way for a long time (longer than it is indicated in the sales contract). This is due to the loss of the quality of 
raw materials required for production in accordance with the technology. To take this feature into account, a modification of the model is required, which can be obtained by introducing a probability distribution characterizing the daily distance traveled by railway, taking into account the season. As we know, the closer to winter, the lower the railway throughput is.

In addition, mention should be made regarding changes in production processes, as a result of which production costs are reduced: $A_{l k}^{m+1}=\max \left(0, A_{l k}^{m}-\varepsilon_{l k}\right)$, where $A_{l k}^{m}-$ volume consumption of recourse $l$ to manufacture item type $k$ in day $m ; \varepsilon_{l k}-$ random non-negative value. Taking into account the likelihood of a change in production technology there is a significant modification of the model. In a competitive environment, when modeling production processes and raw material supply chains, this becomes one of the key factors.
This article considers an enterprise that does not have its own plots. However, it should be borne in mind that in the future the enterprise may receive its own plots, which will also have a qualitative impact on its pricing and resource policies.

In addition, it is necessary to test the solution obtained on the basis of the constructed model. Such a solution can be unstable if prices and volume of demand change dynamically. To do this, it is necessary to enter stochastic values (calculate different price vectors for each type of goods on every day) and resume calculations many times (most likely in parallel ${ }^{12}$ ). This will undoubtedly significantly increase the load on the processor and RAM. Also, the question of a method for solving such problems remains open, since nonlinear and/or stochastic problems do not have a unified approach to their solution $[1,4,16]$.

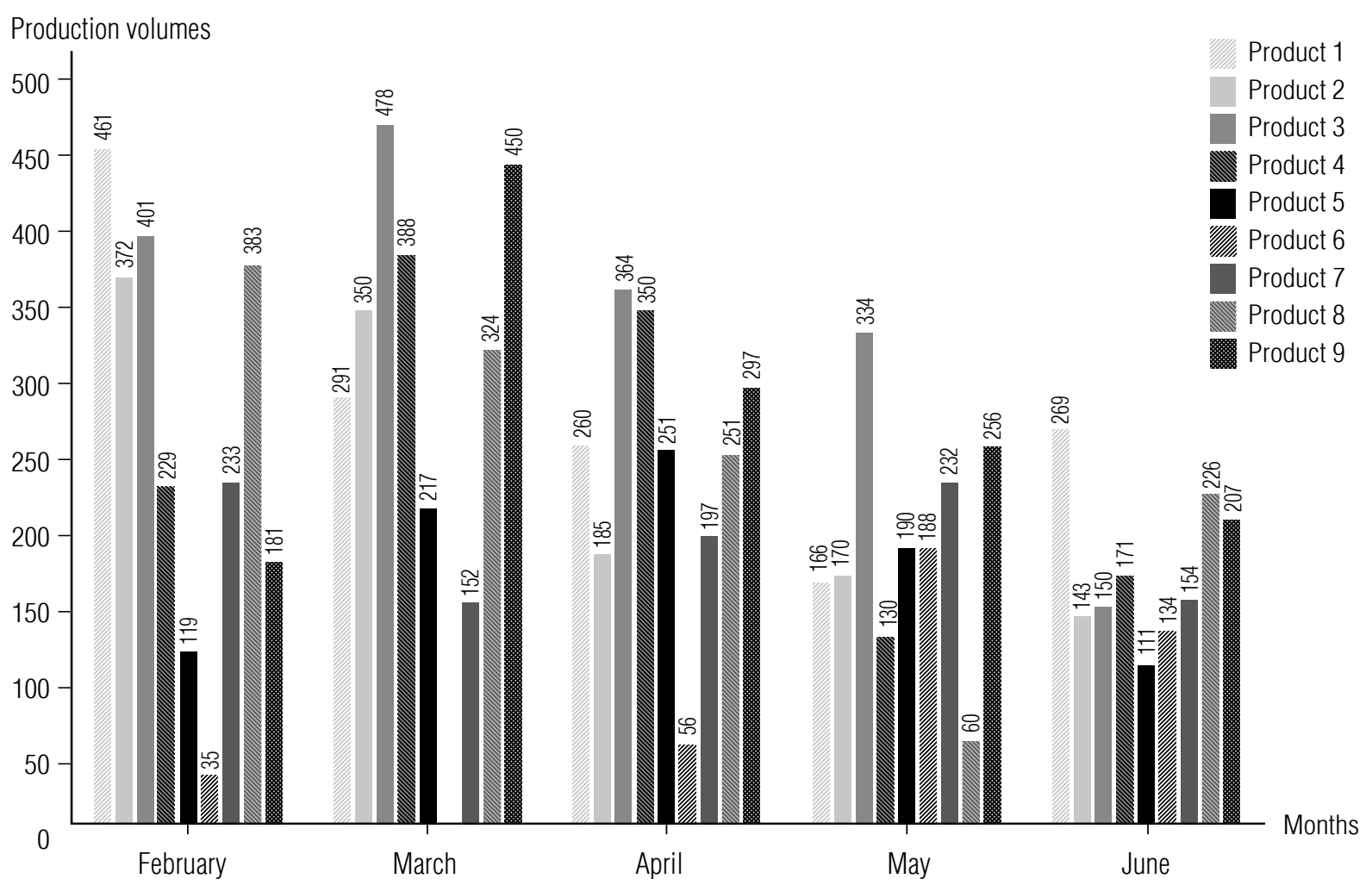

Fig. 7. Visualization of production volumes of each product of the enterprise by month

\footnotetext{
${ }^{12}$ Parallel programming: http://www.ccas.ru/mmes/distcompbook.pdf
} 


\section{Conclusion}

This paper proposes a model for the formation of sustainable supply chains of raw materials for a timber processing enterprise. The model allows us to maximize the value of pre-tax profits and is a mathematical programming problem, characterized by the ability simultaneously to take into account, on the one hand, production rates of consumption of raw materials for the production of final products, and on the other hand, the formation of a vector for purchasing raw materials on a commodity exchange. The solution to the model is the structure of production, the sequence of purchasing raw materials by production on the commodity exchange and the value of profit on each individual day of the enterprise. The process of finding an optimal solution to a problem is complicated by its large dimension, integer constraints, and a rapidly growing load on RAM. To solve such problems, it is worth using combined algorithms. The work implements the two-stage Gomorri method. From a practical point of view, the model is a tool that allows you to form an optimal production plan based on production factors and the volume of raw materials supply on the commodity exchange within the entire planning horizon. In the absence of the possibility of attracting capital from the outside, the model allows you to find the optimal solution that enables the enterprise to avoid a cash gap.

The model was tested on the example of a timber processing complex from Primorsky Territory. On the basis of the calculations performed and the obtained solution, recommendations were formulated for the management of the company on cooperation with the commodity exchange. Analysis of the decision showed that, despite the territorial proximity of the Irkutsk Region to the Primorsky Territory, it makes sense to pay attention to the purchase of raw materials from the Perm Territory, where there is sufficient raw material potential and a more acceptable pricing policy is observed. Analysis has shown that the production of most types of goods should be reduced as summer approaches, due to the seasonality of demand and production of raw materials. In general, the above calculations allow us to draw conclusions about the possibility of rational procurement of raw materials on the commodity exchange.

To analyze qualitatively more complex business processes of an enterprise, it makes sense to modify the model by introducing probabilistic economic and production factors. However, in this case, the question of a method for solving a complicated problem remains open.

\section{Acknowledgments}

The author expresses his gratitude to the company "DNS Wood" LLC for the information provided, as well as to its General Director N. Timokhodtsev and the head of the Timber and Production Department A. Sychikov. The author also expresses gratitude to his scientific advisor - Head of the Department of Mathematics and Modeling of the Vladivostok State University of Economics and Service, Doctor of Economics L.S. Mazelis.

\section{References}

1. Kogler C., Rauch P. (2018) Discrete event simulation of multimodal and unimodal transportation in the wood supply chain: A literature review. Silva Fennica, vol. 52, no 4, article ID 9984. DOI: 10.14214/sf.9984.

2. Haddouch H., Beidouri Z., El Oumami M. (2019) Supply chain management: A review of approaches, practices and impact on performance. International Journal of Supply Chain Management, vol. 8, no 6, pp. 1-13.

3. Escorcia-Caballero J.P., Moreno-Luzon M.D., Chams-Anturi O. (2019) Supply chain integration capability: An organizational routine perspective. International Journal of Supply Chain Management, vol. 8, no 5, pp. 39-47.

4. Rogulin R.S., Nechayev P.V., Pleshanov D.Ye., Yevdakimova N.S., Goncharov Ye.D., Maksimenko V.I. (2018) Complex optimization problem of production-transport processes. Prikladnaya Informatika - Applied Informatics, no 6, pp. 133-141 (in Russian). 
5. Mishra D., Gunasekaran A., Papadopoulos T., Childe S.J. (2018) Big Data and supply chain management: A review and bibliometric analysis. Annals of Operations Research, vol. 270, no 1, pp. 313-336. DOI: $10.1007 / \mathrm{s} 10479-016-2236-\mathrm{y}$.

6. Tuljak-Suban D. (2016) Food supply chain: A review of approaches which enhance sustainability with a focus on social responsibility. Available at: https://www.intechopen.com/books/sustainable-supply-chain-management/ food-supply-chain-a-review-of-approaches-which-enhance-sustainability-with-a-focus-on-social-respons (accessed 01 July 2020). DOI: 10.5772/62536.

7. Cundiff J.S., Dias N., Sherali H.D. (1997) A linear programming approach for designing a herbaceous biomass delivery system. Bioresource Technology, vol. 59, no 1, pp. 47-55. DOI: S0960-8524(96)00129-0.

8. Zarrinpoor N. (2019) A chance-constrained fuzzy programming approach for a sustainable supply chain network design under multiple sources of uncertainty. International Journal of Supply and Operations Management, vol. 6, no 4, pp. 349-359. DOI: 10.22034/2019.4.5.

9. Eliasson L., Eriksson A., Mohtashami S. (2017) Analysis of factors affecting productivity and costs for a high-performance chip supply system. Applied Energy, vol. 185, part 1, pp. 497-505. DOI: $10.1016 / j$.apenergy.2016.10.136.

10. Amrouss A., El Hachemi N., Gendreau M., Gendron B. (2017) Real-time management of transportation disruptions in forestry. Computers \& Operations Research, vol. 83, pp. 95-105. DOI: 10.1016/j. cor.2017.02.008.

11. Altiparmak F., Gen M., Lin L., Paksoy T. (2006) A genetic algorithm approach for multi-objective optimization of supply chain networks. Computers \& Industrial Engineering, vol. 51, no 1, pp. 196-215. DOI: 10.1016/j.cie.2006.07.011.

12. Hnaien F., Delorme X., Dolgui A. (2010) Multiobjective optimization for inventory control in two-level assembly systems under uncertainty of lead times. Computers \& Operations Research, vol. 37, no 11, pp. 1835-1843. DOI: 10.1016/j.cor.2009.06.002.

13. Prakash A., Chan F.T.S., Liao H., Deshmukh S.G. (2012) Network optimization in supply chain: a KBGA approach. Decision Support Systems, vol. 52, no 2, pp. 528-538. DOI: 10.1016/j.dss.2011.10.024.

14. Shi S., Liu Z., Tang L., Xiong J. (2017) Multi-objective optimization for a closed-loop network design problem using an improved genetic algorithm. Applied Mathematical Modelling, vol. 45, pp. 14-30. DOI: j.apm.2016.11.004. DOI: j.apm.2016.11.004.

15. Marufuzzaman M., Eksioglu S.D., Huang Y. (2014) Two-stage stochastic programming supply chain model for biodiesel production via wastewater treatment. Computers \& Operations Research, vol. 49, pp. 1-17. DOI: j.cor.2014.03.010.

16. Rogulin R.S., Maksimenko V.I., Zlobina D.V., Zhandarmov V.O., Pugacheva E.S., Matveev V.V. (2019) The task of combinatorial optimization: The search for an optimal production and transport plan when organizing production in new territories. Bulletin of Ural Federal University. Series Economics and Management, vol. 18, no 3, pp. 364-377 (in Russian). DOI: 10.15826/vestnik.2018.17.3.018.

17. Rabiee M., Zandieh M., Ramezani P. (2012) Bi-objective partial flexible job shop scheduling problem: NSGA-II, NRGA, MOGA and PAES approaches. International Journal of Production Research, vol. 50, no 24, pp. 7327-7342. DOI: 10.1080/00207543.2011.648280.

18. Srinivas N., Deb K. (1994) Multiobjective optimization using nondominated sorting in genetic algorithms. Journal of Evolutionary Computation, vol. 2, no 3, pp. 221-248.

19. Bandyopadhyay S., Bhattacharya R. (2014) Solving a tri-objective supply chain problem with modified NSGA-II algorithm. Journal of Manufacturing Systems, vol. 33, no 1, pp. 41-50. DOI: j.jmsy.2013.12.001.

\section{Rodion S. Rogulin}

\section{About the author}

Doctoral Student, Department of Mathematics and Modeling, Vladivostok State University of Economics and Service, 41, Gogolya Street, Vladivostok 690014, Russia;

Assistant Professor, Department of Applied Mathematics, Mechanics, Control and Software, Far Eastern Federal University, 10, Ajax Bay, Russky Island, Vladivostok 690922, Russia;

E-mail: rafassiaofusa@mail.ru

ORCID: 0000-0002-3235-6429 